\title{
The chlorination transformation characteristics of benzophenone-4 in the presence of iodide ions
}

\author{
Fan Yang ${ }^{1,2}$, Dongbin Wei ${ }^{1,2, *}$, Ming Xiao ${ }^{1,2}$, Xuefeng Sun ${ }^{1,2}$, Qiaorong Guo ${ }^{1,2}$, \\ Yi Liu ${ }^{3}$, Yuguo $\mathrm{Du}^{1,2}$ \\ 1. State Key Laboratory of Environmental Chemistry and Ecotoxicology, Research Center for Eco-Environmental Sciences, Chinese Academy of Sciences, \\ Beijing 100085, China. E-mail: yangfan715@mails.ucas.ac.cn \\ 2. University of Chinese Academy of Sciences, Beijing 100049, China \\ 3. College of Chemistry and Chemical Engineering, Yantai University, Yantai, Shandong Province 264005, China
}

\section{A R T I C L E I N F O}

Article history:

Received 16 January 2017

Revised 8 April 2017

Accepted 20 April 2017

Available online 3 May 2017

Keywords:

Benzophenone

Chlorination

Iodinated disinfection by-products

Mechanism

Toxicity

\begin{abstract}
A B S T R A C T
Benzophenone-type UV filters are a group of compounds widely used to protect human skin from damage of UV irradiation. Benzophenone-4 (BP-4) was targeted to explore its transformation behaviors during chlorination disinfection treatment in the presence of iodide ions. With the help of ultra performance liquid phase chromatograph and high-resolution quadrupole time-of-flight mass spectrometer, totally fifteen halogenated products were identified, and five out of them were iodinated products. The transformation mechanisms of BP-4 involved electrophilic substitution generating mono- or di-halogenated products, which would be oxidized into esters and further hydrolyzed into phenolic derivatives. The desulfonation and decarboxylation were observed in chlorination system either. Obeying the transformation pathways, five iodinated products formed. The $\mathrm{pH}$ conditions of chlorination system determined the reaction types of transformation and corresponding species of products. The more important was that, the acute toxicity had significant increase after chlorination treatment on BP-4, especially in the presence of iodide ions. When the chlorination treatment was performed on ambient water spiked with BP-4 and iodide ions, iodinated by-products could be detected.
\end{abstract}

(c) 2017 The Research Center for Eco-Environmental Sciences, Chinese Academy of Sciences. Published by Elsevier B.V.

\section{Introduction}

With the rapid deterioration of the global climate, the depletion of the ozone layer becomes an extremely serious problem. Consequently, the UV (ultraviolet) irradiation level to the earth and the exposure dose to human body has significant increased, which can cause skin darkening and injury or even skin cancer. In recent decades, UV filters have been widely used not only in personal care products, such as cosmetics, lotions, lipsticks and shampoos (Roelandts et al., 1983; Diaz-Cruz et al., 2008; Fent et al., 2010; Manová et al.,
2013), but also in pharmaceuticals, insecticides, and agricultural chemicals. The permitted maximum content of some UV filters may be up to $10 \%$ of the product weight (SJP, 1985; TGA, 2003). With the routine activities of human beings, such as bathing, swimming, leaching of land, house coating and effluent discharging from wastewater treatment plants, UV filters enter into the environment (Kasprzyk-Hordern et al., 2008a; Poiger et al., 2004; Giokas et al., 2007). Benzophenone-type compounds (BPs), one of the major classes of UV filters, are able to protect human skin from the harms of UVA (ultraviolet A, 320-400 nm) and UVB (ultraviolet B, 290-

\footnotetext{
* Corresponding author. E-mail: weidb@rcees.ac.cn (Dongbin Wei).
} 
$320 \mathrm{~nm})$ (Moloney et al., 2002). BP-3 (2-hydroxy-4-methoxy-BP) and BP-4 (2-hydroxy-4-methoxy-5-sulfonic acid-BP) have been approved as additives of sunscreens by the European Legislation (Shaath, 2007). The maximum concentrations of BP-4 permitted in cosmetics are $10 \%, 10 \%, 5 \%$ and $5 \%$ in Japan, Australia, China and EU respectively (SJP, 1985; TGA, 2003; EEC, 1983; $\mathrm{MOH}, 2007)$. It was reported that the residual concentrations of BP-4 were at hundreds of $\mathrm{ng} / \mathrm{L}$ in river and sea water, and ranged from 237 to $1481 \mathrm{ng} / \mathrm{L}$ in wastewater samples (Rodil et al., 2008). On the other hand, BP-4 levels in the inlet and outlet streams of activated sludge sewage plants were over 5 and $4 \mu \mathrm{g} /$ L, respectively (Kasprzyk-Hordern et al., 2008b). This result suggested that BP-4 was stable enough to survive from the conventional biodegradation processes (Rodil et al., 2008). The residue of benzophenones in the environment would pose potential risk to fish and other organisms (Zucchi et al., 2011). Many reports showed that BP-type chemicals exhibited multiple biological effects, such as exerting uterotrophic effect in vivo (Kawamura et al., 2003), increasing the secretion of the tumor marker pS2 in vitro, and stimulating the proliferation of MCF-7 breast cancer cells (Schlumpf et al., 2001). In particular, a current epidemiological survey showed that BP-2 (2,2' 4,4'-tetrahydroxy-BP) and 4-HBP (4-hydroxy-BP) were associated with $31 \%$ and $26 \%$ reduction in fecundity, respectively (Louis et al., 2014). Therefore, BPs have been defined as "chemicals suspected of having endocrine disrupting effects" by the Japanese Ministry of Environment (MOE, 2000). In addition, some other studies showed that BPs could bioaccumulate in human body, exhibited genotoxicity and reproductive toxicity (Zhao et al., 2013; Krause et al., 2012).

Disinfection with free available chlorine (FAC, $\mathrm{HOCl} / \mathrm{OCl}^{-}$) is the most common method to kill harmful pathogens in water treatment process. Except for killing pathogens, FAC can also react with some residual chemicals in water. Many reports showed that the residual UV filters may undergo chlorination, oxidation and decarboxylation to generate some unintended poisonous disinfection by-products (DBPs) during chlorination disinfection treatment (Xiao et al., 2013; Deborde and von Gunten, 2008; DellaGreca et al., 2009; Dodd and Huang, 2004; Pinkston and Sedlak, 2004; Buth et al., 2007). Recent studies evidenced that some non-regulated DBPs, e.g., halogenated aromatic transformation products, and some regulated DBPs, such as trihalomethanes and haloacetic acids with high toxicity could be formed during chlorination of BPs (Yang and Zhang, 2013; Pan et al., 2016; Liu and Zhang, 2014). Moreover, some inorganic ions in natural aquatic system, such as $\mathrm{Br}^{-}$and $\mathrm{I}^{-}$, would affect the formation of DBPs (Deborde and von Gunten, 2008). It has been reported that the concentration of $\mathrm{I}^{-}$in natural water bodies generally ranges from 0.5 to $20 \mu \mathrm{g} / \mathrm{L}$, even reaches $50 \mu \mathrm{g} / \mathrm{L}$ in offshore surface water and some special geographical regions of the world (Fuge and Johnson, 1986). During the oxidation and disinfection treatment, the disinfectant chlorine oxidizes $\mathrm{I}^{-}$ to hypoiodous acid (HOI) rapidly (Nagy et al., 1988). And HOI would further react with natural organic matter (NOM) or pollutants in water to form iodo-organic compounds. Many kinds of iodinated DBPs, such as iodinated trihalomethanes (Bichsel and von Gunten, 2000) and iodoacetic acid have been detected in drinking water treated with chlorine (Weinberg et al., 2002; Liu et al., 2017; Ye et al., 2013). More importantly, iodinated DBPs usually exhibit higher toxicity than brominated and chlorinated analogs. For example, the toxicity of iodoacetic acid on Chinese hamster ovarian cells is 3.2 and 287.5 fold higher than that of bromoacetic acid and chloroacetic acid, respectively (Plewa et al., 2004).

In our previous study on transformation characteristics of BP-4 in chlorination process, 13 products were identified (Xiao et al., 2013). In the presence of $\mathrm{Br}^{-}, 12$ products containing bromine atom were found in the chlorination system (Xiao et al., 2014; Negreira et al., 2012). Especially, the toxicity of reaction mixture with bromide ions was much higher than reaction mixture without bromide ions (Xiao et al., 2014). Since very little is known about the impacts of iodide ions on the BP-4 chlorination, the objectives of this study were to investigate the formation of transformation products and the acute toxicity variation during chlorination of BP-4 in the presence of iodide ions. Ultra performance liquid phase chromatography in tandem with quadrupole time-of-flight mass spectrometry (UPLC-QTOF-MS) was used for separating and identifying the transformation products, and the possible formation pathways of iodinated products were proposed. Especially, photobacterium bioassay was used for tracing the acute toxicity changes of chlorinated BP-4 in the presence of iodide ions.

\section{Materials and methods}

\subsection{Chemical reagents and instruments}

BP-4 (2-hydroxy-4-methoxy-5-sulfonic acid-benzophenone) was purchased from Sigma-Aldrich (St. Louis, MO, USA). Salts including $\mathrm{HOAc}, \mathrm{NaAc}, \mathrm{Na}_{2} \mathrm{CO}_{3}, \mathrm{NaHCO}_{3}, \mathrm{Na}_{2} \mathrm{HPO}_{4} \cdot 12 \mathrm{H}_{2} \mathrm{O}$ and $\mathrm{KH}_{2} \mathrm{PO}_{4} \cdot 5 \mathrm{H}_{2} \mathrm{O}$ for preparing buffer solutions, $\mathrm{NaCl}$ and $\mathrm{Na}_{2} \mathrm{SO}_{3}$ for preparing toxicity test medium and quenching solutions, were purchased from Sigma-Aldrich (St Louis, MO, USA). The sodium hypochlorite (8\%) aqueous solution was obtained from Wako Co. (Tokyo, Japan). The concentration of chlorine stock solution was determined using the $\mathrm{N}, \mathrm{N}$-diethyl-phenylenediamine ferrous titration method. Methanol (for high performance liquid phase chromatography (HPLC) analysis) was purchased from Fisher Scientific (Fair Lawn, NJ, USA). Formic acid (for HPLC analysis) was purchased from Acros Organics (Belgium, WI, USA). All reagents were diluted with ultrapure water and used without further purification. The test bacteria Photobacteria phosphoreum T3 Straus was provided as freeze-dried powder by the Institute of Soil Science, Chinese Academy Science, Nanjing, China. The ultrapure water used in solution preparation and dilution was produced by a Milli-Q purification system (Millipore, Billerica, MA, USA). An Ultimate 3000 UPLC (Dionex, USA) and QTOF-MS (micrOTOF QII, Bruker, Germany) were used to separate and identify the transformation products of BP-4 during chlorination treatment in the presence of iodide ions.

\subsection{Chlorination experiments}

The experiments were performed in a $1000 \mathrm{~mL}$ of borosilicate glass screw-cap conical flask, which was wrapped with aluminum foil and placed in water bath with a magnetic 
stirring apparatus to maintain the reaction temperature at $25 \pm 0.5^{\circ} \mathrm{C}$. Considering the distribution and properties of FAC and iodine species with $\mathrm{pH}$ conditions (Appendix A Fig. $\mathrm{S} 1)$, experiments were conducted under three different $\mathrm{pH}$ values (pH 4.6, 7.5 and 11.0). The $0.1 \mathrm{~mol} / \mathrm{L}$ of acetate buffer, $0.1 \mathrm{~mol} / \mathrm{L}$ of phosphate buffer, and $0.1 \mathrm{~mol} / \mathrm{L}$ of carbonate buffer were respectively applied for keeping stable $\mathrm{pH}$ conditions during chlorination treatment.

The BP-4 stock solution ( $1 \mathrm{~mol} / \mathrm{L}$ ) was prepared in methanol and KI stock solution was prepared at the concentration of $0.5 \mathrm{~mol} / \mathrm{L}$. In order to easily find the transformation products and have a comprehensive understanding on the reaction mechanisms, the initial concentration of BP-4 and FAC was set at a relatively high level. Reactions were initiated by adding appropriate FAC (molar ratio $\mathrm{FAC}_{0}: \mathrm{BP}-4_{0}=5: 1$ ) to $500 \mathrm{~mL}$ buffer solution containing $5 \mathrm{mmol} / \mathrm{L} \mathrm{BP}-4$ and equivalent molar KI. Five milliliters of samples was taken from the reactor at certain time intervals and slightly excessive sodium sulfite (molar ratio $\mathrm{SO}_{3}^{2-}: \mathrm{FAC}=1.2: 1$ ) was added to sample vials in advance to quench the residual FAC.

\subsection{Sample preparation}

The salts in samples need to be removed due to the adverse effects on acute toxicity test and UPLC-QTOF-MS analysis. First, the samples were dehydrated by a lyophilizer (FD-1D-50, Beijing, China). Then $1 \mathrm{~mL}$ of methanol/acetone (1:1, V/V) was added to extract organic products and the extract was filtered through a $0.22 \mu \mathrm{m}$ glass fiber membrane. The filtrate was equally divided into two parts, one was directly injected to UPLC-QTOF-MS system, and the other was used for acute toxicity test after solvent conversion. The organic solvent was dried with a gentle flow of ultrapure nitrogen gas, and the solid was diluted with water after it was re-dissolved with $200 \mu \mathrm{L}$ DMSO (less than 1\%).

\subsection{Sample detection}

A Dionex Ultimate 3000 UPLC equipped with Agilent SB-C18 column $(4.6 \times 150 \mathrm{~mm}, 5 \mu \mathrm{m})$ was used to separated transformation products. A Bruker micrOTOF QII quadrupole time-of-flight mass spectrometer was applied to identify the structure of these products. Injection volume was $5 \mu \mathrm{L}$ and flow rate was $0.4 \mathrm{~mL} / \mathrm{min}$, mobile phases were formic acid aqueous solution $(0.1 \%, \mathrm{~V} / \mathrm{V})$ and methanol. The gradient elution method is shown in Table S1. The mass spectrometry (MS) analyses were conducted under negative mode electrospray ionization $\left(\mathrm{ESI}^{-}\right)$over a full scan range of 50-1000 m/z. Spray chamber temperature was set as $250^{\circ} \mathrm{C}$ and dry gas flow rate was $6 \mathrm{~L} / \mathrm{min}$. The mass spectrometry fragmentation voltage was set at $175 \mathrm{eV}$.

\subsection{Acute toxicity test}

A photobacterium bioassay method was used to trace the acute toxicity variation of reaction mixture during chlorination treatment. A $3 \%$ of $\mathrm{NaCl}$ solution was set as the negative control, and $\mathrm{Hg}^{2+}$ was set as positive control to obtain a doseresponse calibration curve. The pretreated samples were diluted with $\mathrm{NaCl}$ (3\%) to $180 \mu \mathrm{L}$ and added into 96-well microplate. Then $20 \mu \mathrm{L}$ of pre-cultured P. phosphoreum bacteria was added into each well. After 15 min shaking at $20^{\circ} \mathrm{C}$, the bioluminescence intensity was measured by Synergy ${ }^{\mathrm{TM}}$ 2 Multi-Mode Microplate Reader (Biotek, Shoreline, WA, USA). Toxicity was expressed as inhibition ratio (IR, \%) of luminescence intensity, which could be described as below equivalent:

$\mathrm{IR}=\frac{\mathrm{L}_{\mathrm{NC}}-\mathrm{L}_{\mathrm{sample}}}{L_{\mathrm{NC}}} \times 100 \%$

where, $L_{\text {sample }}$ represents luminescence intensity of samples, and $L_{N C}$ represents luminescence intensity of negative control.

\section{Results and discussion}

\subsection{Identification of transformation products}

The effects of iodide ions on BP-4 chlorination were investigated under a wide range of $\mathrm{pH}$ values $(4.6,7.5,11.0)$. The samples were analyzed under certain gradient elution condition using UPLC-QTOF-MS. The total ion chromatograms (with full scan mode) of BP-4 chlorination mixture under different $\mathrm{pH}$ conditions are shown in Appendix A Fig. S2. Based on the peaks in the chromatograms, 15 major transformation products were detected and listed in Table 1. Peaks of all products were separated completely and chromatographic signals were significant enough for qualitative analysis. It was obvious that the transformation behaviors of BP-4 in the presence of iodide ions were strongly dependent on the $\mathrm{pH}$ conditions.

Among the 15 products, five iodide-containing products (P1, P2, P3, P8, P14) were identified and their MS, MS/MS spectra are shown in Appendix A Figs. S3 and S4, respectively. The high-resolution mass spectrometer (resolution $>16,500$ FWHM (full width at half maximum) and $\Delta \mathrm{M} / \mathrm{M}<2 \mathrm{ppm}$ ) can provide accurate mass and isotopic information, and the MS/ MS spectra can provide fragmentation information of parent ions for defining the molecular structure of transformation products. For example, the exact molecular weight of P4 (mono-chlorinated product) is $\mathrm{m} / \mathrm{z} 341.9965 / 343.9935$ and the intensity ratio of isotopic peaks is $3: 1$. It can be inferred that one hydrogen atom was substituted by one chlorine atom on the benzene ring. Due to the orientation effect of ortho hydroxy and methoxy groups, the electrophilic chlorine atom easily attacks carbon atom on the 3-position to form P4. Moreover, P5 and P5' has one more oxygen atom than P4, which was attributed to the oxidation of ketone group into ester group by FAC. This reaction is named as Baeyer-Villiger oxidation which has been reported in our previous study (Xiao et al., 2013).

\subsection{Possible transformation pathways}

The chlorination disinfection experiments of BP-4 were conducted under different $\mathrm{pH}$ values $(4.6,7.5$ and 11.0). It was observed that the transformation products of BP-4 were strongly dependent on the operating conditions. Fig. 1 shows the relative content variation of parent and major transformation products during chlorination process at $\mathrm{pH} 4.6,7.5$ and 11.0 respectively. Since 10 of transformation products, 
Table 1 - Major transformation products of chlorination of benzophenone- 4 in the presence of iodide ions.

Pect $\begin{gathered}\text { Exact } \\ \text { mass }\end{gathered}$

including all of iodinated transformation products, were detected under neutral condition, the outcomes at $\mathrm{pH} 7.5$ were taken as example to illustrate the transformation mechanisms of BP-4 in the presence of iodide ions. It can be seen from Fig. 1b, that ca. $75 \%$ of BP-4 degraded rapidly within the first $5 \mathrm{~min}$, and then slowly decreased. The monoiodinated product $\mathrm{P} 1$ rapidly formed within the first $5 \mathrm{~min}$, reached maximum level at about $30 \mathrm{~min}$, and then slowly decreased to the end of the reaction, implying that P1 was further transformed into some other products. Correspondingly, the mono-iodinated ester product $\mathrm{P} 2$ reached its maximum in the initial $5 \mathrm{sec}$ and then decreased in the following $2 \mathrm{hr}$, its hydrolysis product P3 and di-halogenated product P14 increased gradually. The formation and transformation patterns of chlorinated products were similar with those of iodinated products. Moreover, comparing to the formation characteristics of transformation products at $\mathrm{pH} 7.5$, the similar cases were observed at pH 4.6 (Fig. 1a) and pH 11 (Fig. 1c), although the species of transformation products were less at pH 4.6 and 7.5. It can be concluded that the first halogenation readily took place than the secondary substitution in the presence of iodide ions, while oxidation and ester hydrolysis reactions easily occurred. The species and relative content of iodinated products were less than those of chlorinated products.

Based on the structures of products detected by UPLCQTOF-MS and reaction principles of BP-4, the possible formation pathways of BP-4 during chlorination in the presence of iodide ions were proposed (Fig. 2). As mentioned above, iodide ions would be readily oxidized into HOI with FAC, $\mathrm{HOI}$ and $\mathrm{HOCl}$ would competitively react with BP-4 and its intermediates. Firstly, electrophilic halogen atoms in $\mathrm{HOCl}$ or $\mathrm{HOI}$ would attack carbon atom at 3-position on the benzene ring due to the orientation effect of ortho hydroxy and methoxy groups with electronic-donating effect, forming mono-chlorinated (P4) or mono-iodinated products (P1). Secondly, halogenated keto-type products could undergo Baeyer-Villiger oxidation by hypohalous acid (HOX) to form ester products (Gordon and Evans, 1993). Considering the migratory aptitude of two benzene rings of BP-4, there were two ways for oxygen atom to insert at either side of the ketone group. One was to insert between ketone group and 1-C, to form $\mathrm{P} 5$, the other was to insert between ketone group and $1^{\prime}-\mathrm{C}$ to form $\mathrm{P} 5$ '. Thirdly, the ester product P5 could take place secondary halogenation at 6-C to form di-halogenated product P9, which could subsequently undergo nucleophilic hydrolysis to form phenolic-type product (e.g., P11) and carboxylic-type product. Fourthly, the carboxylic-type product readily occurred decarboxylation and halogen substitution.

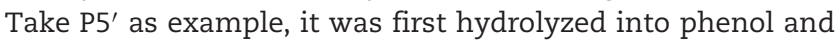
carboxylic-type product, then the carboxylic-type product would further undergo decarboxylation and chlorination (or iodination) to form chlorinated product P6 (or iodinated product P8). Fifthly, the sulfonic group in BP-4 and intermediates could be electrophilic substituted by a chlorine atom to form P13 only under acidic condition (Gilbert, 1965). Additionally, P11 could be further oxidized to form five-member heterocyclic furan-like product P12 because of Baeyer-Villiger oxidation and subsequent condensation under acidic condition (Xiao et al., 2013).

Five iodide-containing products were found in the BP-4 chlorination mixtures, P1, P2, P8, P14 were mono-iodinated while $\mathrm{P} 3$ was di-iodinated products. The formation of iodinated products was mainly attributed to the electrophilic substitution of BP-4 with HOI, and subsequent oxidation and hydrolysis. However, due to the active chemical properties, $\mathrm{HOI}$ could be oxidized into $\mathrm{IO}_{3}^{-}$with $\mathrm{HOCl}$ (Bichsel and von Gunten, 1999), which would decrease the relative concentrations of FAC ( $\mathrm{HOCl}$ and $\mathrm{HOI})$ in the chlorination system, hinder the further transformation of BP-4 and its intermediates.

It is well known that the distribution and properties of FAC and iodine are dependent on the $\mathrm{pH}$ conditions (Appen$\operatorname{dix}$ A Fig. S1), therefore, the experiments were conducted under different $\mathrm{pH}$ conditions to verify the behaviors of BP-4 and formation pathways of iodinated products. It can be seen from Appendix A Fig. S2, the formation of products in chlorination systems under acid, neutral and alkaline conditions are quite different. The effects of $\mathrm{pH}$ values on the transformation of BP-4 can be summed up in two. First, $\mathrm{pH}$ could influence the transformation pathways of BP-4. As shown in Appendix A Fig. S5, BP-4 in the iodide-containing system underwent more types of transformation reactions 

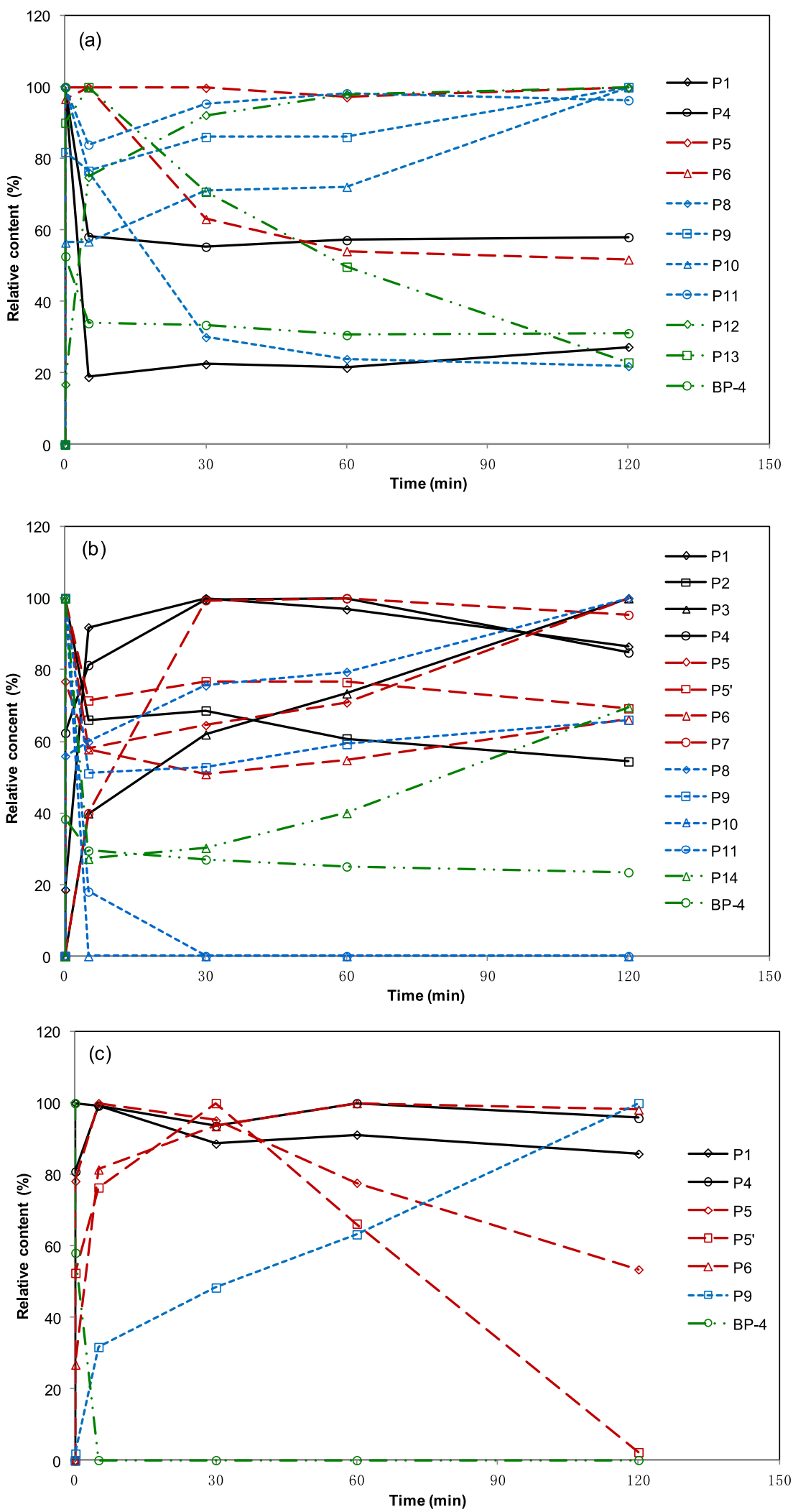

Fig. 1 - Formation and relative contents of main products of benzophenone-4 chlorination under three $\mathrm{pH}$ systems ((a) $\mathrm{pH} 4.6$; (b) $\mathrm{pH} 7.5 ;$ (c) $\mathrm{pH} 11.0$ ) in the presence of iodide ions (benzophenone- $4_{0}: 5 \mathrm{mmol} / \mathrm{L} ; \mathrm{I}^{-}{ }_{0}: 5 \mathrm{mmol} / \mathrm{L}$; free available chlorine $_{0}$ : $25 \mathrm{mmol} / \mathrm{L}$ ). The relative content for each product was calculated through standardizing peak area. 


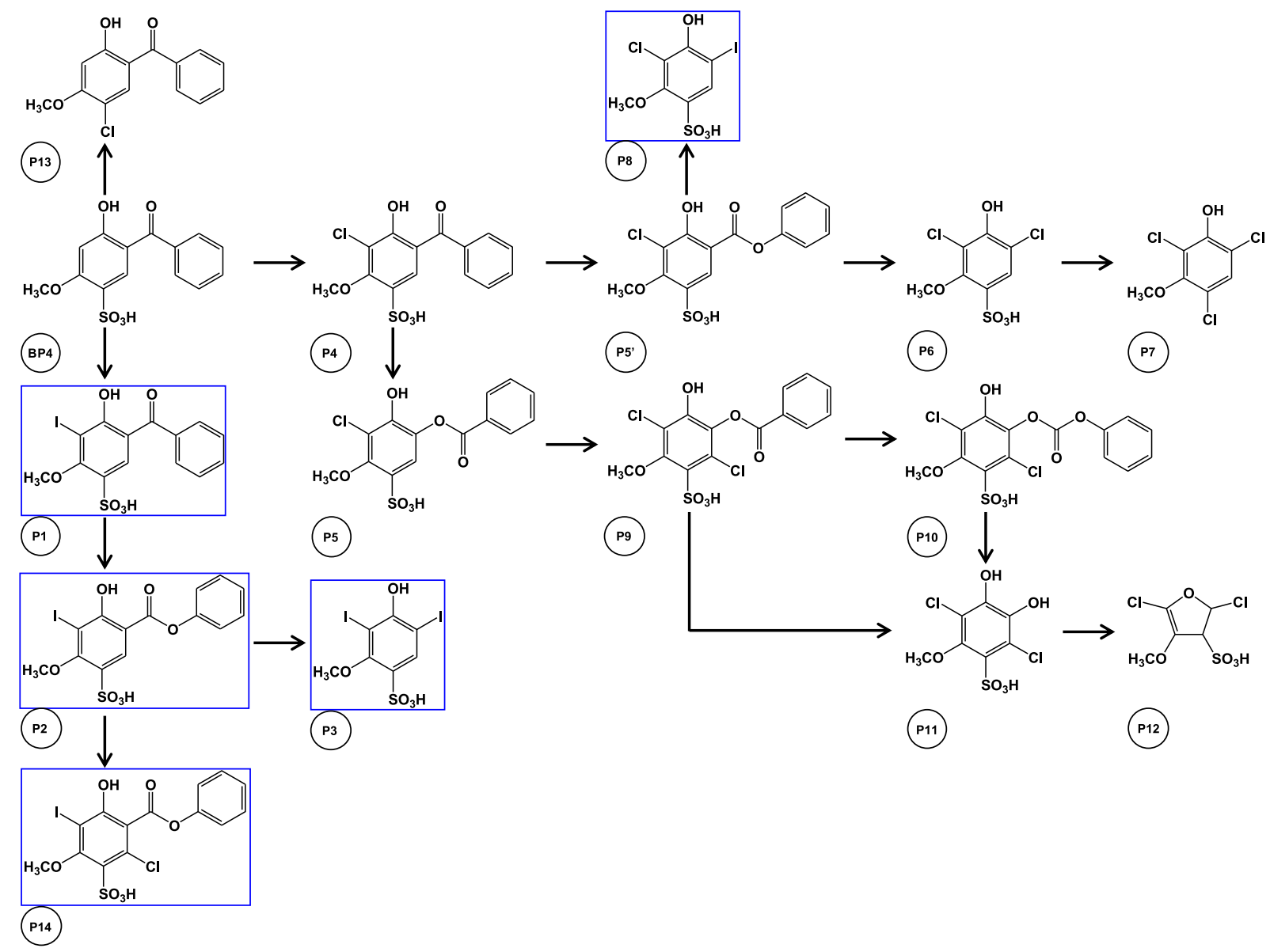

Fig. 2 - The proposed transformation pathways of benzophenone-4 chlorination in the presence of iodide ions (benzophenone- $4_{0}: 5 \mathrm{mmol} / \mathrm{L}, \mathrm{I}_{0}^{-}: 5 \mathrm{mmol} / \mathrm{L}$, free available chlorine $\mathrm{e}_{0}: 25 \mathrm{mmol} / \mathrm{L}$, reaction time: $2 \mathrm{hr}$ ).

(e.g., chlorination, oxidation and hydrolysis) at $\mathrm{pH} 4.6$ and 7.5 than those at $\mathrm{pH}$ 11.0. This phenomenon was similar to the transformation characteristics of BP-4 in chlorination system without iodide ions (Xiao et al., 2013). On the one hand, in alkaline system, $\mathrm{OCl}^{-}$and $\mathrm{OI}^{-}$were the predominant species of $\mathrm{HOCl}$ and $\mathrm{HOI}$ respectively, which have lower reactivity. As a result, only mono-halogenated products were formed, while the further transformation was hindered. On the other hand, iodide ions in the system would be first oxidized into $\mathrm{HOI}$ with $\mathrm{HOCl}$, and $\mathrm{HOI}$ could be further oxidized into $\mathrm{IO}_{3}^{-}$ when the excess $\mathrm{HOCl}$ oxidant existed in the system (Bichsel and von Gunten, 1999). All these reactions consumed not only reactive substance, $\mathrm{HOI}$, but also oxidant $\mathrm{HOCl}$ in the chlorination system. Therefore, the formation of some products was inhibited due to the complicated competitive reactions. The extent of inhibition was determined by the oxidation rate of $\mathrm{HOI}$ and reaction rate of $\mathrm{BP}-4$ with reactive constituents in the system.

Second, $\mathrm{pH}$ determined the reaction rate of BP-4. At $\mathrm{pH} 4.6$, only $69 \%$ of BP-4 was eliminated in the initial $2 \mathrm{hr}$, while $78 \%$ and $100 \%$ at pH 7.5 and $\mathrm{pH} 11$, respectively. It is well known that, at $\mathrm{pH} 4.6$ and $7.5, \mathrm{HOCl}$ and $\mathrm{HOI}$ were the dominant species with high reactivity, which could react with both BP-4 and its intermediates. Thus, some reactive intermediates would compete FAC with BP-4, and the degradation percentage of $\mathrm{BP}-4$ was lower at $\mathrm{pH} 4.6$ and 7.5 than that at $\mathrm{pH}$ 11. However, in alkaline system, $\mathrm{OCl}^{-}$and $\mathrm{OI}^{-}$were the major oxidants, they only react with parent BP-4, while hardly react with intermediates of $\mathrm{BP}-4$. Therefore, the transformation of parent BP-4 was more thorough at $\mathrm{pH} 11.0$, whereas, the species of products were less than those at $\mathrm{pH} 4.6$ and 7.5.

\subsection{Acute toxicity variation}

The photobacterium bioassay was used to trace the acute toxicity variation of BP-4 after chlorination in the presence of iodide ions. The time-dependent acute toxicity changes under different $\mathrm{pH}$ conditions are shown in Fig. 3. It can be seen that, at the same diluted level (all of the samples were similarly diluted 60 times for toxicity test), the acute toxicity of samples taken from the different $\mathrm{pH}$ values was quite different. With the increase of $\mathrm{pH}$ values, the acute toxicity decreased. This phenomenon may be relevant to the different content of predominant transformation products in reaction mixtures. Under acid and neutral conditions, intermediates of BP-4 could further reacted with $\mathrm{HOCl}$ and HOI, to form di-halogenated ester products (P9, P14) and their hydrolysis products (P3, P11) or even five-member heterocyclic furan-like product (P12). As a result, the acute toxicity was a little high. On the contrary, it was difficult for 

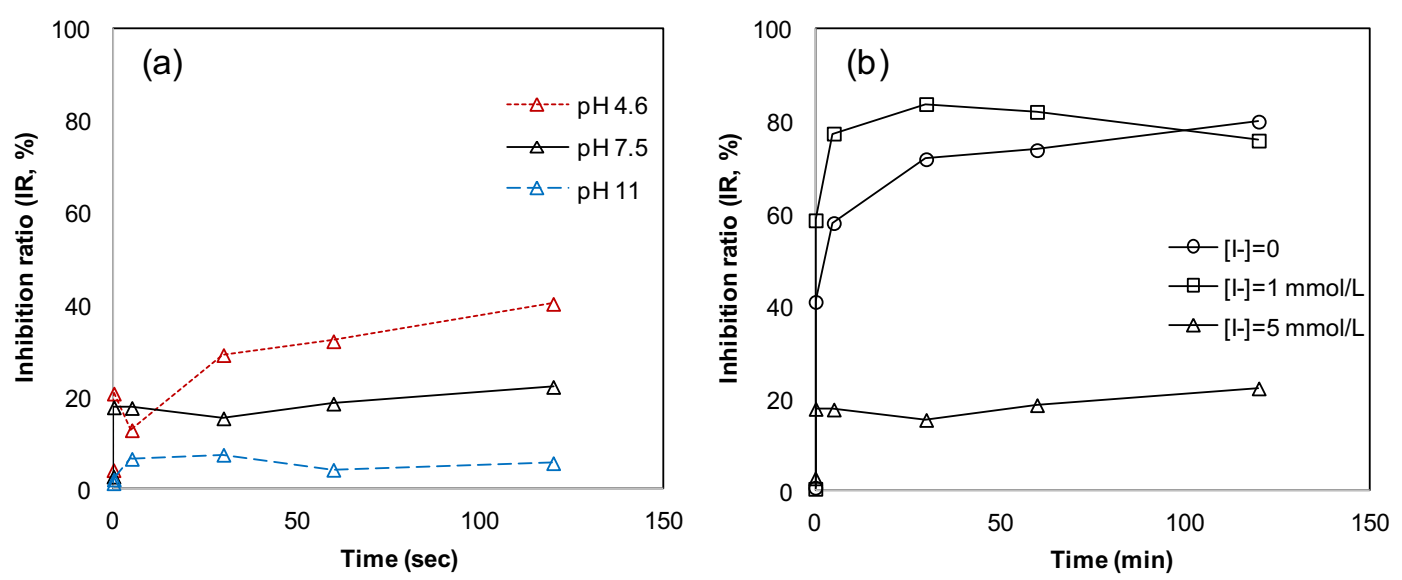

Fig. 3 - Acute toxicity of reaction mixtures of benzophenone-4 chlorination systems in the presence of iodide ions ((a) benzophenone- $4_{0}: 5 \mathrm{mmol} / \mathrm{L}, \mathrm{I}^{-}{ }_{0}: 5 \mathrm{mmol} / \mathrm{L}$, free available chlorine $\mathrm{e}_{0}: 25 \mathrm{mmol} / \mathrm{L}$; (b) benzophenone-4 $\mathbf{0}_{0}: 5 \mathrm{mmol} / \mathrm{L}$, free available chlorine $\left.\mathrm{o}_{0}: 25 \mathrm{mmol} / \mathrm{L}, \mathrm{pH} 7.5\right)$.

intermediates of BP-4 to undergo further transformation at $\mathrm{pH} 11$, and therefore acute toxicity was relatively lower than the other two $\mathrm{pH}$ conditions.

Although the acute toxicity had some difference for the samples from three $\mathrm{pH}$ conditions, the relative inhibition ratio of acute toxicity was not high compared to the previous results of BP-4 chlorination without iodide ions yet (Xiao et al., 2013, 2014). A possible fact was concerned, that was, the presence of iodide ions would consume the available amount of $\mathrm{HOCl}$ in the chlorination system (Bichsel and von Gunten, 1999). Appendix A Fig. S6 showed the time-dependent concentration changes of BP-4 in the chlorination disinfection systems with and without iodide ions. The presence of iodide ions greatly reduced the removal percentage of BP-4. If the toxicity would be higher when the iodide concentration was decreased? The experiments were conducted in three different iodide concentrations $(0,1,5 \mathrm{mmol} / \mathrm{L}$, respectively). The acute toxicity changes under different conditions are shown in Fig. 3b. It can be observed that the acute toxicity of sample with $1 \mathrm{mmol} / \mathrm{L}$ iodide ions was much higher than that with $5 \mathrm{mmol} / \mathrm{L}$ of iodide ions, even high than that without iodide ions. This could be explained that the iodinated products contributed the extra toxicity when FAC was excess. However, the toxicity was significantly decreased when the concentration of iodide ions increased. Because BP-4 could not be completely eliminated under this condition due to the competitive reactions between $\mathrm{I}^{-}$, HOI and FAC.

\subsection{Environmental significance}

All the experiments above were conducted in pure water, if the transformation could be repeated in ambient water system still remains unknown. Thus, two ambient water samples were applied to conduct simulation experiments. One sample was secondary effluent of one wastewater treatment plant of Beijing (total organic carbon (TOC) was $18.86 \mathrm{mg} / \mathrm{L}, \mathrm{pH}$ value was 8.2, ammonia-nitrogen $\left(\mathrm{NH}_{3}-\mathrm{N}\right)$ was $0.65 \mathrm{mg} / \mathrm{L}$, total dissolved solid (TDS) was $1400 \mathrm{mg} / \mathrm{L}$ ), and the other sample was tap water in laboratory (TOC = $\left.1.04 \mathrm{mg} / \mathrm{L}, \quad \mathrm{pH}=7.1, \quad \mathrm{NH}_{3}-\mathrm{N}=0.12 \mathrm{mg} / \mathrm{L}, \quad \mathrm{TDS}=252 \mathrm{mg} / \mathrm{L}\right)$. $\mathrm{BP}-4$ and iodide ions were spiked into the ambient water samples, and the chlorination experiments were conducted. As shown in Fig. 4, P1 and P4 were found in both samples after chlorination treatment with the presence of iodide ions, while P5, P6, and P9 were only found in tap water matrix. The occurrence of chlorinated and iodinated products suggested that, similar transformation of BP-4 could be repeated in ambient water chlorination process in the presence of iodide ions. In some seawater swimming pools, the proposed formation mechanisms of iodinated and chlorinated products might be replayed in the water containing both BP-4 and $\mathrm{I}^{-}$ion. Moreover, it has been reported that HOI can react with natural organic materials to form iodo-chloroform (Bichsel and von Gunten, 2000). In our previous study (Xiao et al., 2013, 2014), some chlorinated and brominated products of BP-4 was directly detected in concentrated swimming pool water samples. In a word, the proposed mechanisms were able to occur, accompanying formation of halogenated products, and the potential risk of benzophenone-type UV filters should be taken with great concern.

\section{Conclusions}

This study discovered the transformation behaviors of BP-4 during the chlorination treatment in the presence of iodide ions. Totally fifteen halogenated products were identified, and five of them were newly discovered iodinated products. The possible transformation pathways of BP-4 chlorination were proposed, including five types of mechanisms, i.e., electrophilic halogenation, Baeyer-Villiger oxidation, hydrolysis, desulfonation and decarboxylation. The $\mathrm{pH}$ values greatly determined the transformation pathways and species of products. The presence of iodide ions increased competitive reactions in chlorination system, and inhibited the transformation efficiency of BP-4. The similar transformation 


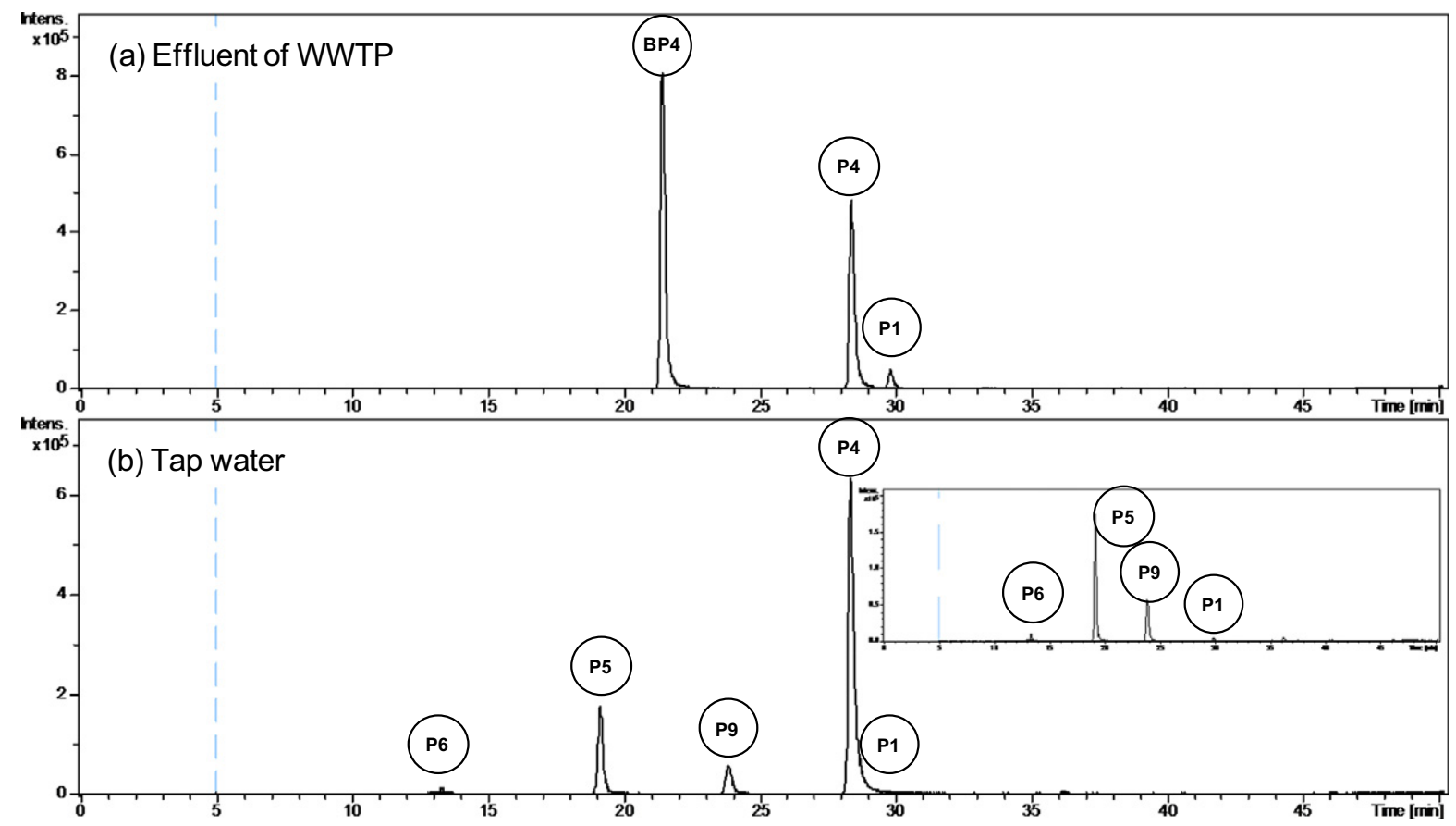

Fig. 4 - The major products detected within chlorination systems of ambient water matrices spiked with benzophenone-4 and iodide ions. (a) Effluent of wastewater treatment plant (total organic carbon concentration is $18.86 \mathrm{mg} / \mathrm{L}, \mathrm{pH}$ value is 8.2 , ammonia-nitrogen concentration is $0.65 \mathrm{mg} / \mathrm{L}$, total dissolved solid content is $1400 \mathrm{mg} / \mathrm{L}$ ); (b) Tap water (total organic carbon concentration is $1.04 \mathrm{mg} / \mathrm{L}, \mathrm{pH}$ value is 7.1 , ammonia-nitrogen concentration is $0.12 \mathrm{mg} / \mathrm{L}$, total dissolved solid content is $252 \mathrm{mg} / \mathrm{L}$ ) (Experimental conditions: benzophenone-4 ${ }_{0}: 2 \mu \mathrm{g} / \mathrm{mL}, \mathrm{I}_{0}^{-}: 2 \mu \mathrm{g} / \mathrm{mL}$, free available chlorine $\mathrm{e}_{0}: 2.5 \mu \mathrm{g} / \mathrm{mL}, \mathrm{reaction}$ time: $0.5 \mathrm{hr}$ ).

of BP-4 could be occurred in real ambient water samples, P1 (mono-iodinated BP-4) and P4 (mono-chlorinated BP-4) were detected in both two ambient water during the chlorination process with the presence of iodide ions. More importantly, the acute toxicity increased significantly after chlorination, especially in the presence of a small quantity of iodide ions. The present study would throw more light on the transformation characteristics of benzophenone-type UV filters in chlorination disinfection practices, and provide a scientific evidence for optimizing the operating parameters for chlorination disinfection process and evaluating potential risk of benzophenone-type UV filters.

\section{Acknowledgments}

This work was supported by the National Natural Science Foundation of China (Nos. 21577154, 21377143, 21590814, and 21402192), and the Strategic Priority Research Program of the Chinese Academy of Sciences (No. XDB14040201).

\section{Appendix A. Supplementary data}

Supplementary data to this article can be found online at http://dx.doi.org/10.1016/j.jes.2017.04.023.
R E F E R E N C E S

Bichsel, Y., von Gunten, U., 1999. Oxidation of iodide and hypoiodous acid in the disinfection of natural waters. Environ. Sci. Technol. 33 (22), 4040-4045.

Bichsel, Y., von Gunten, U., 2000. Formation of iodo-trihalomethanes during disinfection and oxidation of iodide containing waters. Environ. Sci. Technol. 34 (13), 2784-2791.

Buth, J.M., Arnold, W.A., Mcneill, K., 2007. Unexpected products and reaction mechanisms of the aqueous chlorination of cimetidine. Environ. Sci. Technol. 41, 6228-6233.

Deborde, M., von Gunten, U., 2008. Reactions of chlorine with inorganic and organic compounds during water treatment-kinetics and mechanisms, a critical review. Water Res. 42, 13-51.

DellaGreca, M., Iesce, M.R., Pistillo, P., Previtera, L., Temussi, F., 2009. Unusual products of the aqueous chlorination of atenolol. Chemosphere 74, 730-734.

Diaz-Cruz, M.S., Llorca, M., Barcelo, D., 2008. Organic UV filters and their photodegradates, metabolites, and disinfection byproducts in the aquatic environment. Trends Anal. Chem. 27 (10), 873-887.

Dodd, M.C., Huang, C.H., 2004. Transformation of the antibacterial agent sulfamethoxazole in reactions with chlorine, kinetics, mechanisms, and pathways. Environ. Sci. Technol. 38, 5607-5615.

EEC (European Economic Community), 1983. Council Directive 83/574/EEC of 26 October 1983 Amending for the Third Time 
Directive 76/768/EEC on the Approximation of the Laws of the Member States Relating to Cosmetic Products. Vol. 332 pp. 38-42.

Fent, K., Zenker, A., Rapp, M., 2010. Widespread occurrence of estrogenic UV-filters in aquatic ecosystems in Switzerland. Environ. Pollut. 158, 1817-1824.

Fuge, R., Johnson, C.C., 1986. The geochemistry of iodine-a review. Environ. Geochem. Health 8, 31-54.

Gilbert, E.E., 1965. Sulfonation and related reactions. Interscience Publishers, New York, pp. 1-529.

Giokas, D.L., Salvador, A., Chisvert, A., 2007. UV filters, from sunscreens to human body and the environment. Trends Anal. Chem. 26 (5), 360-374.

Gordon, N.J., Evans, S.A., 1993. Acyl phosphates from acyl phosphonates - A novel Baeyer -Villiger rearrangement. J. Org. Chem. 58 (17), 4516-4519.

Kasprzyk-Hordern, B., Dinsdale, R.M., Guwy, A.J., 2008a. The occurrence of pharmaceuticals, personal care products, endocrine disruptors and illicit drugs in surface water in South Wales, UK. Water Res. 42 (13), 3498-3518.

Kasprzyk-Hordern, B., Dinsdale, R.M., Guwy, A.J., 2008 b. Multiresidue methods for the analysis of pharmaceuticals, personal care products and illicit drugs in surface water and wastewater by solid-phase extraction and ultra performance liquid chromatography-electrospray tandem mass spectrometry. Bioanal. Chem. 391, 1293-1308.

Kawamura, Y., Ogawa, Y., Nishimura, T., Kikuchi, Y., Nishikawa, J., Nishihara, T., et al., 2003. Estrogenic activities of UV stabilizers used in food contact plastics and benzophenone derivatives tested by the yeast two-hybrid assay. J. Health Sci. 49, 205-212.

Krause, M., Klit, A., Blomberg Jensen, M., Søeborg, T., Frederiksen, H., Schlumpf, M., Lichtensteiger, W., Skakkebaek, N.E., Drzewiecki, K.T., 2012. Sunscreens: are they beneficial for health? An overview of endocrine disrupting properties of UV-filters. Int. J. Androl. 35, 424-436.

Liu, J.Q., Zhang, X.R., 2014. Comparative toxicity of new halophenolic DBPs in chlorinated saline wastewater effluents against a marine alga: halophenolic DBPs are generally more toxic than haloaliphatic ones. Water Res. 65, 64-72.

Liu, S.G., Li, Z.L., Dong, H.Y., Goodman, B.A., Qiang, Z.M., 2017. Formation of iodo-trihalomethanes, iodo-acetic acids, and iodo-acetamides during chloramination of iodide-containing waters: factors influencing formation and reaction pathways. J. Hazard. Mater. 321, 28-36.

Louis, G.M.B., Kannan, K., Sapra, K.J., Maisoj, J., Sundaram, R., 2014. Urinary concentrations of benzophenone-type ultraviolet radiation filters and couples' fecundity. Am. J. Epidemiol. 180 (12), 1168-1175.

Manová, E., von Goetz, N., Hauri, U., Bogdal, C., Hungerbühler, K., 2013. Organic UV filters in personal care products in Switzerland: a survey of occurrence and concentrations. Int. J. Hyg. Environ. Health 216, 508-514.

Ministry of Environment (MOE), 2000. MOE's perspectives on endocrine disrupting effects of substances - Strategic Programs on Environmental Endocrine Disruptors (SPEED'98). http://www.env.go.jp/chemi/end/endindex.html, (Japan).

MOH (Ministry of Health), 2007. Hygienic Standard for Cosmetics. Ministry of Health, Beijing, China.

Moloney, F.J., Collins, S., Murphy, G.M., 2002. Sunscreens: safety, efficacy and appropriate use. Am. J. Clin. Dermatol. 3 (3), 185-191.

Nagy, J.C., Kumar, K., Margerum, D.W., 1988. Non-metal redox kinetics-oxidation of iodide by hypochlorous acid and by nitrogen trichloride measured by the pulsed-accelerated-flow method. Inorg. Chem. 27 (16), 2773-2780.

Negreira, N., Rodríguez, I., Rodil, R., Cela, R., 2012. Assessment of benzophenone-4 reactivity with free chlorine by liquid chromatography quadrupole time-of-flight mass spectrometry. Anal. Chim. Acta 743, 101-110.
Pan, Y., Zhang, X.R., Li, Y., 2016. Identification, toxicity and control of iodinated disinfection byproducts in cooking with simulated chlor(am)inated tap water and iodized table salt. Water Res. $88,60-68$.

Pinkston, K.E., Sedlak, D.L., 2004. Transformation of aromatic ether-and amine-containing pharmaceuticals during chlorine disinfection. Environ. Sci. Technol. 38, 4019-4025.

Plewa, W.J., Wagner, E.D., Richardson, S.D., Thruston, A.D., Woo, Y.T., McKague, A.B., 2004. Chemical and biological characterization of newly discovered iodo-acid drinking water disinfection byproduct. Environ. Sci. Technol. 38 (18), 4713-4722.

Poiger, T., Buser, H.R., Balmer, M.E., Bergqvist, P.A., Muller, M.D., 2004. Occurrence of UV filter compounds from sunscreens in surface waters, regional mass balance in two Swiss lakes. Chemosphere 55 (7), 951-963.

Rodil, R., Quintana, J.B., Lopez-Mahia, P., Muniategui-Lorenzo, S., Prada-Rodriguez, D., 2008. Multiclass determination of sunscreen chemicals in water samples by liquid chromatography-tandem mass spectrometry. Anal. Chem. 80, 1307-1315.

Roelandts, R., Vanhee, J., Bonamie, A., Kerkhofs, L., Degreef, H., 1983. A survey of ultraviolet absorbers in commercially available sun products. Int. J. Dermatol. 22 (4), 247-255.

Schlumpf, M., Cotton, B., Conscience, M., Haller, V., Steinmann, B., Lichtensteiger, W., 2001. In vitro and in vivo estrogenicity of UV screens. Environ. Health Perspect. 109, 239-244.

Shaath, N.A., 2007. The Encyclopedia of Ultraviolet Filters. Allured Publishing Corporation, Dallas, TX, USA, p. 222.

SJP (The Society of Japanese Pharmacopoeia), 1985. Japanese Standard of Cosmetic Ingredients. second ed. Yakuji Nippo Ltd., Tokyo, Japan.

TGA (Therapeutic Goods Administration), 2003. Australian Regulatory Guidelines for OTC Medicines. Therapeutic Goods Administration, Australia.

Weinberg, H.S., Krasner, S.W., Richardson, S.D., Thruston, A.D., 2002. The Occurrence of Disinfection By-product (DBPs) of Health Concern in Drinking Water: Results of a Nationwide DBP Occurrence Study. National Exposure Research Laboratory. Office of Research and Development, US Environment Protection Agency.

Xiao, M., Wei, D.B., Yin, J.X., Wei, G.H., Du, Y.G., 2013. Transformation mechanism of benzophenone-4 in free chlorine promoted chlorination disinfection. Water Res. 47, 6223-6233.

Xiao, M., Wei, D.B., Li, L.P., Liu, Q., Zhao, H.M., Du, Y.G., 2014. Formation pathways of brominated products from benzophenone-4 chlorination in the presence of bromide ions. J. Environ. Sci. 26, 2378-2396.

Yang, M.T., Zhang, X.R., 2013. Comparative developmental toxicity of new aromatic halogenated DBPs in a chlorinated saline sewage effluent to the marine polychaete Platynereis dumerilii. Environ. Sci. Technol. 47 (19), 10868-10876.

Ye, T., Xu, B., Lin, Y.L., Hu, C.Y., Lin, L., Zhang, T.Y., Gao, N.Y., 2013. Formation of iodinated disinfection by-products during oxidation of iodide-containing waters with chlorine dioxide. Water Res. 47, 3006-3014.

Zhao, H.M., Wei, D.B., Li, M., Du, Y.G., 2013. Substituent contribution to the genotoxicity of benzophenone-type UV filters. Ecotoxicol. Environ. Saf. 95, 241-246.

Zucchi, S., Blüthgen, N., Ieronimo, A., Fent, K., 2011. The UV-absorber benzophenone-4 alters transcripts of genes involved in hormonal pathways in zebrafish (Danio rerio) eleuthero-embryos and adult males. Toxicol. Appl. Pharmacol. 250, 137-146. 